\title{
Optical Coherence Tomography for Study of In Vivo Pathobiology and for Optimization of Percutaneous Coronary Intervention
}

\author{
Tomoyo Sugiyama, MD, $\mathrm{PhD},{ }^{1} \mathrm{Ik}-$ Kyung Jang, $\mathrm{MD}, \mathrm{PhD}^{1,2^{*}}$ \\ ${ }^{1}$ Cardiology Division, Massachusetts General Hospital, Harvard Medical School, Boston, MA, USA \\ ${ }^{2}$ Division of Cardiology, Kyung Hee University Hospital, Seoul, Republic of Korea
}

\begin{abstract}
Intravascular optical coherence tomography (OCT) is an imaging modality uniquely characterized by its high resolution. OCT can visualize in vivo plaque characteristics and detect vulnerable plaque, such as thin-cap fibroatheroma, which has a large lipid pool with overlying thin fibrous cap. OCT can also help the clinicians to identify the underlying pathology of acute coronary syndrome: plaque rupture, plaque erosion, and calcified nodule. The OCT system enables automated measurement of the lumen diameter, lumen area, and lesion length, which is useful to determine appropriate reference sites, stent size and stent length during percutaneous coronary intervention (PCI). Evaluation of underlying plaque characteristics is helpful in predicting possible complications after PCI. OCT-guided PCI may acquire comparable angiographical and clinical outcomes to intravascular ultrasound-guided PCI. OCT can be used to evaluate characteristics of non-culprit plaque and efficacy of lipidlowering therapy on plaque stabilization. OCT also clearly visualizes mechanical vessel injury after stent implantation. Notably, the presence of irregular tissue protrusion has been shown to be associated with the occurrence of device-oriented clinical events. Recent studies suggest that OCT is feasible for the selection of conservative management without stenting in patients with acute coronary syndrome caused by plaque erosion.
\end{abstract}

Key words: optical coherence tomography, percutaneous coronary intervention

\section{Introduction}

It has been 40 years since the first balloon coronary angioplasty procedure was performed. ${ }^{1)}$ Since then, development of treatment devices such as bare metal stents, ${ }^{2)}$ drug-eluting stents, ${ }^{3)}$ and bioresorbable vascular scaffolds ${ }^{4)}$ has dramatically changed the management of patients with coronary artery disease. Intracoronary imaging modalities such as intravascular ultrasound (IVUS), developed in the late 1980s and utilized in clinical practice since the 1990s, ${ }^{5-8)}$ and coronary angioscopy (CAS), developed in the early $1990 \mathrm{~s},{ }^{9-11)}$ have been used to enrich our understanding of in vivo pathology of coronary atherosclerosis as well as to improve the outcomes of percutaneous coronary intervention (PCI). Optical coherence tomography (OCT) was first developed for ex vivo imaging of the atherosclerotic plaque in the

\footnotetext{
* 55 Fruit Street GRB 800, Boston, MA 02114, USA

Tel: +1-617-726-9226; Fax: +1-617-726-7416

e-mail: ijang@mgh.harvard.edu

(Received: 2017.08.17; Accepted: 2017.11.10)

doi.org/10.15791/angioscopy.re.17.0020
}

1990s. ${ }^{12-14)}$ After ex vivo validation by autopsy specimen, ${ }^{15)}$ the first-in-man study was conducted at the Massachusetts General Hospital to evaluate the feasibility of OCT to visualize plaque components in the coronary arteries. ${ }^{16)}$ The first-generation time-domain OCT became commercially available in 2002. The second-generation frequency-domain (Fourier-domain) OCT was introduced in 2010 with occlusion-free imaging, improved pull-back speed with higher frame rate, and increased axial scan density for improved image quality. The latest model of OCT (C8 ILUMIEN OPTIS PCI Optimization System, St. Jude Medical, Inc., St. Paul, MN, USA) provides imaging with a faster pull-back speed of $18-36 \mathrm{~mm} / \mathrm{s}$ (180 frames/s), greater pull-back length of 54-75 mm, and real-time three-dimensional image reconstruction.

\section{In Vivo Plaque Characterization}

The strength of OCT imaging is its high resolution (10-20 $\mu \mathrm{m}),{ }^{17)}$ which has enabled visualization of coronary artery structures and plaque characteristics such as fibrous, fibrocalcific, and lipid-rich plaques (Fig. 1), ${ }^{15)}$ and established the measurement of 

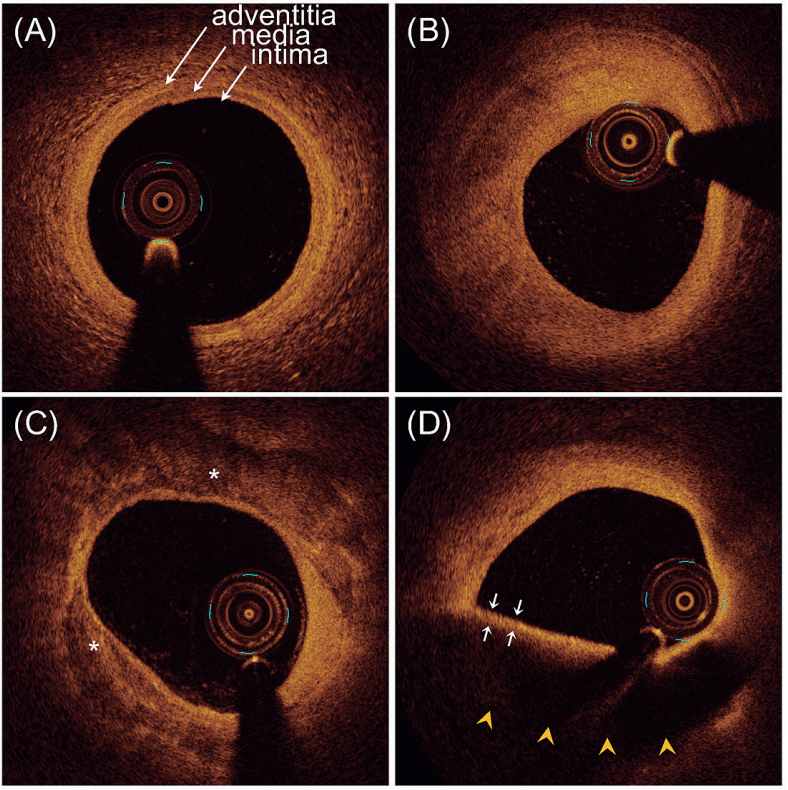

Fig. 1 Plaque characterization by optical coherence tomography.

(A) Normal coronary artery wall consists of three layers: intima, media, and adventitia.

(B) Fibrous plaque is characterized by a homogenous, signal-rich region.

(C) Fibrocalcific plaque shows well-delineated, signal-poor regions with sharp borders (asterisk).

(D) Lipid-rich plaque is characterized by signal-poor lipid pool with diffuse borders (arrow head) with an overlying fibrous cap (arrow). fibrous cap overlying lipid-rich plaques. ${ }^{18)}$ OCT has also enabled in vivo detection of vulnerable plaques such as thin-cap fibroatheromas (TCFA), defined as plaques with large lipid pool and overlying thin fibrous cap, ${ }^{19)}$ that are prone to rupture and suggestive of plaque vulnerability. ${ }^{20)}$ Fibrous cap thickness on OCT is correlated to CAS-derived yellow grade of plaque, ${ }^{21)}$ which suggests large lipid pool on histological examination. ${ }^{22)}$ OCT is the only intravascular imaging modality able to visualize coexisting features of plaque instability such as macrophage accumulation, ${ }^{23)}$ microvessel, ${ }^{24)}$ and cholesterol crystals. ${ }^{19,25)}$ OCT can also detect intraluminal thrombus and classify its components into white (platelet-rich) thrombus and red (erythrocyte-rich) thrombus based on material structure and signal intensity attenuation. $^{26,27)}$

\section{Detection of Culprit Plaque Morphologies in Acute Coronary Syndrome}

Pathology reports have shown that there are three major underlying mechanisms for acute coronary thrombosis contributing to acute coronary syndrome (ACS) and sudden cardiac death: plaque rupture, plaque erosion, and calcified nodule (Fig. 2). ${ }^{20,28)}$ OCT is feasible to detect culprit plaque morphologies in patients with ACS. ${ }^{29)}$ The most frequent etiology of ACS is plaque rupture (Fig. 2A). OCT can clearly visualize plaque ruptures as fibrous cap discontinuity with cavity formation. ${ }^{19,29)}$ The incidence of plaque rupture is mainly determined by fibrous cap thickness, and a combination of large plaque burden and luminal narrowing leads to plaque rupture in patients with ACS. ${ }^{30}$ Plaque rupture is more frequently observed in culprit plaques of patients with ST-segment-elevation myocardial infarction
(STEMI) compared to those with non-ST-segment-elevation acute coronary syndrome (NSTE-ACS). ${ }^{31)}$ Patients with plaque rupture have greater pancoronary vulnerability and systemic inflammation. ${ }^{32,33)}$

OCT has also allowed in vivo diagnosis of plaque erosion (Fig. 2B). ${ }^{34)}$ Despite its high resolution, current OCT system cannot image the detachment of endothelial cells. ${ }^{35)}$ OCT-erosion has been classified based on the absence of fibrous cap disruption and the presence of thrombus: definite OCT-erosion identified by the presence of attached thrombus overlying an intact and visualized plaque; and probable OCT-erosion defined by i) luminal surface irregularity at the culprit lesion in the absence of thrombus; or ii) attenuation of underlying plaque by thrombus without superficial lipid or calcification immediately proximal or distal to the site of thrombus. ${ }^{34)}$ There have been no distinct morphological features identified as precursors of plaque erosion. $^{36)}$

OCT-derived calcified nodule (Fig. 2C) has been defined as fibrous cap disruption over calcified plaque with thrombus attachment, which is characterized by protruding calcification, superficial calcium, and the presence of substantive calcium proximal and/or distal to the lesion. ${ }^{34)}$ Thus far, no systematic study of OCT-derived calcified nodules has been published.

There are several other causes of ACS. Spontaneous coronary artery dissection can be clearly visualized with the appearance of double-lumen (true and false lumens) or intramural hematoma. ${ }^{37)}$ OCT may help to make stenting approach possible such as sealing the intimal tear to close the entry of dissection. ${ }^{38)}$ Coronary spasm-induced ACS is commonly accompanied by intraluminal thrombus and erosion on OCT, ${ }^{39,40)}$ but it remains un- 

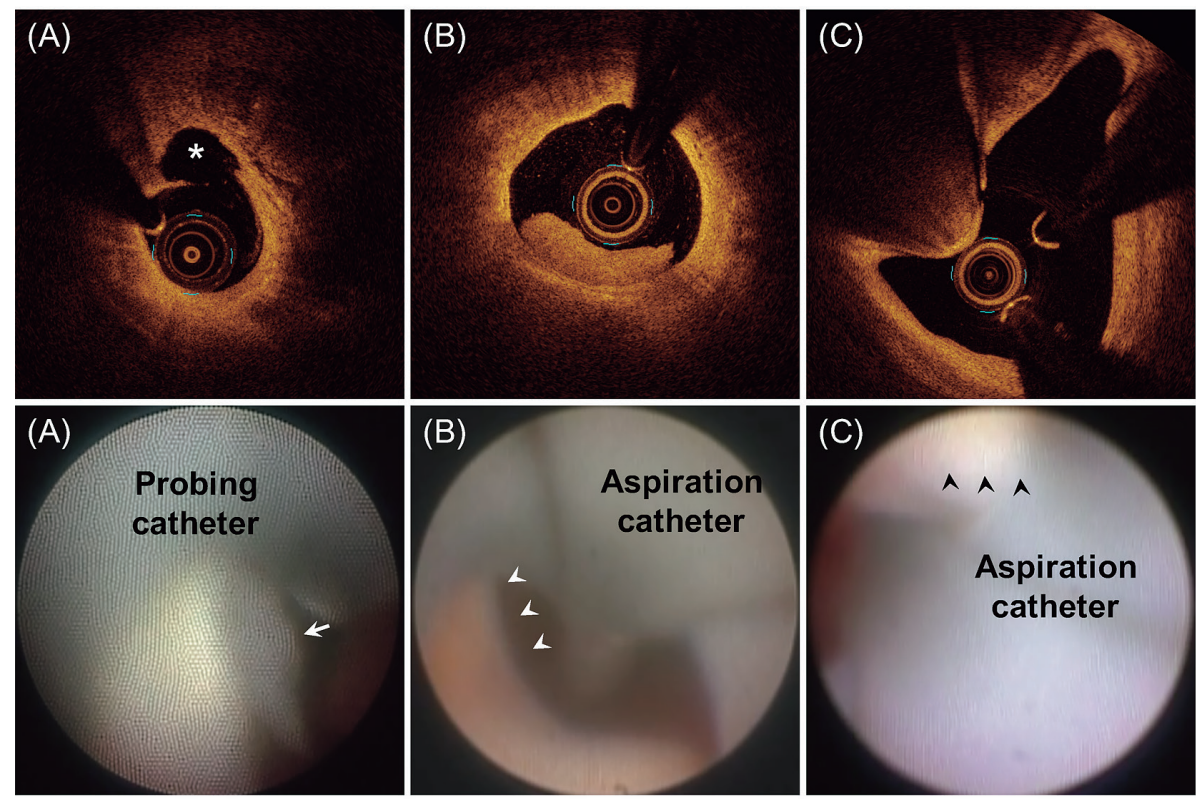

Fig. 2 Representative images of culprit plaque morphologies of acute coronary syndrome on optical coherence tomography (OCT) (upper row) and coronary angioscopy (CAS) (lower row). Figure courtesy of Dr. Shigeki Kimura.

(A) Plaque rupture is characterized by fibrous cap discontinuity with cavity formation (asterisk) on OCT and fibrous cap disruption protruding into the lumen (arrow) on CAS.

(B) Plaque erosion is identified by the presence of attached thrombus overlying an intact and visualized plaque on OCT, or if the plaque shows surface erosion with no evidence of disrupted fibrous cap protruding into the lumen on CAS (white arrowhead).

(C) Calcified nodule is defined as fibrous cap disruption over calcified plaque on OCT. In this case, CAS indicates light yellow mass on the surface (black arrowhead).

certain whether repeated spasm may cause plaque erosion or vice versa.

\section{OCT Guidance for PCI}

OCT system enables automated measurement of the lumen diameter and lumen area in each cross-sectional frame, and lesion length by the longitudinal view. These measurements are useful to determine appropriate reference sites, stent size, and stent length during PCI. The presence of lipidic plaque and fibrocalcific plaque at the stent edge is associated with the higher incidence of stent edge dissection than fibrous plaques. ${ }^{41,42)}$ The presence of lipidic plaque at the stent edge is also reportedly associated with post-PCI myocardial infarction ${ }^{43)}$ and stent edge restenosis. ${ }^{44)}$ Therefore, selecting healthy landing zones is preferred for optimal stent deployment. ${ }^{45}$ )

The evaluation of underlying plaque characteristics is also important to predict worse outcomes after PCI. The presence of OCT-derived TCFA is associated with the occurrence of no-reflow phenomenon, ${ }^{46)}$ post-PCI myocardial injury/infarction, ${ }^{47-49)}$ and microvascular obstruction on cardiac magnetic resonance imaging. ${ }^{50)}$ Greater amount of residual thrombus burden after aspiration thrombectomy is related to worse microvascular dys- function and greater post-PCI myocardial injury. ${ }^{51)}$

Usefulness of OCT guidance for PCI has been evaluated in several studies. In the retrospective CLI-OPCI study, OCTguided PCI was associated with a significantly lower one-year risk of the composite of cardiac death, myocardial infarction, or repeat revascularization compared to angiography-guided PCI. ${ }^{52)}$ In the ILUMIEN I study, PCI optimization based on pre-PCI and post-PCI OCT was associated with reduced rates of postPCI myocardial infarction. ${ }^{53)}$ The ILUMIEN II study reported OCT guidance was associated with comparable stent expansion to IVUS guidance. ${ }^{54)}$ The DOCTORS study demonstrated that OCT-guided PCI was associated with higher post-PCI fractional flow reserve than angiography-guided PCI. ${ }^{55)}$ The OPINION trial demonstrated non-inferiority of optical frequency-domain imaging-guided PCI compared to IVUS-guided PCI with regard to the incidence of target vessel failure for 1 year $^{56)}$ and the acquisition of comparable minimal lumen area at 8-month follow-up OCT ${ }^{57)}$ The ILUMIEN III: OPTIMIZE PCI study was the first randomized controlled trial that compared OCT-guided, IVUS-guided, and angiography-guided PCI. In this study, OCT guidance showed similar angiographical and clinical outcomes, and non-inferiority in achieving similar minimal stent area, 
compared to IVUS guidance. ${ }^{58)}$ Larger randomized controlled trials are warranted to evaluate whether OCT-guided PCI yields superior outcomes to IVUS-guided or angiography-guided PCI.

\section{Evaluation of Non-culprit Plaque Characteristics}

OCT has an advantage in evaluating the characteristics in non-culprit plaques. The greater vulnerability in non-culprit plaques is observed in patients with ACS, ${ }^{59)}$ diabetes mellitus, ${ }^{60,61)}$ and chronic kidney disease. ${ }^{62)}$ A recent study showed that the presence of non-culprit lipid-rich plaque in PCI-treated vessels was associated with non-culprit lesion-related future events. ${ }^{63)}$ These studies suggest that OCT can identify patients at high risk in the future. ${ }^{64)}$ Efficacy of medical therapy can be also evaluated by OCT. More intensive lipid-lowering therapy with statins has been associated with an increase in fibrous cap thickness and decrease in lipid arc in non-culprit plaques, which may lead to plaque stabilization. ${ }^{65-67)}$

\section{Post-stent OCT Findings on Outcomes after $\mathrm{PCl}$}

IVUS-guided PCI has been shown to reduce major adverse cardiac events (MACE) including target lesion revascularization and stent thrombosis in the era of second-generation drug-eluting stents (DES) ${ }^{68)}$ On the other hand, attempts to show the strength of OCT-guided PCI over IVUS-guided PCI on longterm outcomes have not been successful. Suboptimal stent deployment with unsatisfactory minimal stent area on OCT is associated with increased risk of MACE. ${ }^{69)}$ OCT clearly and sensitively visualizes mechanical vessel injury after stent implantation such as stent edge dissection, incomplete stent apposition, and tissue protrusion ${ }^{70,71)}$ in higher frequency compared to
IVUS. ${ }^{72,73)}$ OCT is capable of detecting smaller stent edge dissection (Fig. 3A) than IVUS, ${ }^{74}$ but OCT-detected stent edge dissection is not associated with the clinical events. ${ }^{73-77)}$ Incomplete stent apposition (Fig. 3B) may be related to persistent malapposition, ${ }^{75)}$ or delayed neointimal coverage, ${ }^{78)}$ but small incomplete stent apposition is not related to clinical events. ${ }^{73-76,79)}$ Tissue protrusion (Fig. 3C) may be related to neointimal hyperplasia, ${ }^{80)}$ but does not affect the occurrence of clinical events either. ${ }^{72-76,80-82)}$ Notably, the presence of irregular tissue protrusion, which suggests deep vessel injury and underlying large lipid components, has been shown to be associated with the occurrence of device-oriented clinical events for 1 year. $^{76,83)}$ So far, the way to prevent the incidence of irregular tissue protrusion or to treat irregular protrusion after PCI remains undetermined.

\section{Tailored Management in Patients with Plaque Erosion}

Currently, patients with ACS have been uniformly treated with stent implantation. ${ }^{84,85)}$ Recent studies suggest that conservative management without stenting may be an option in patients with ACS caused by plaque erosion. ${ }^{86,87)}$ OCT is the only intracoronary imaging device that can visualize plaque erosion owing to its high resolution. The EROSION study has shown the feasibility and safety of anti-thrombotic therapy without stenting in patients with ACS caused by plaque erosion. ${ }^{86}$ The use of OCT may bring a major shift in the management away from routine stenting toward more tailored management in patients with plaque erosion.
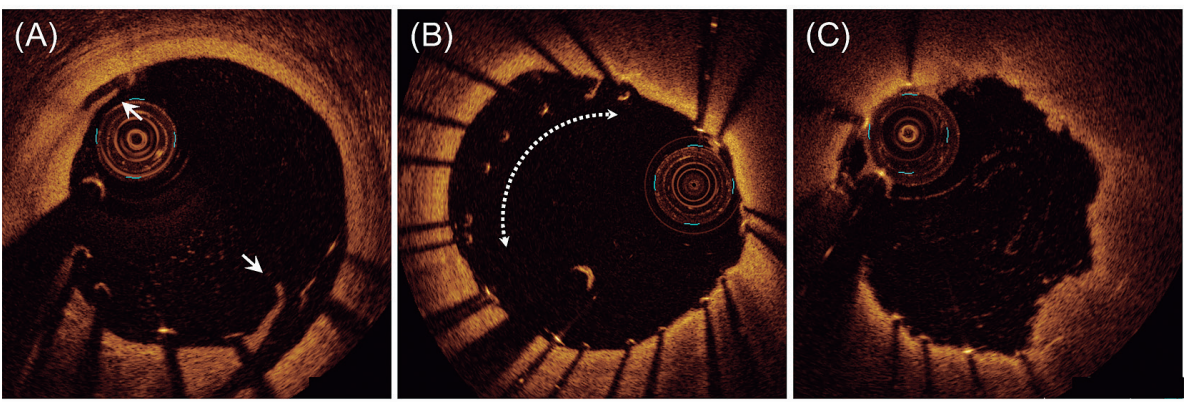

Fig. 3 Post-stent findings on optical coherence tomography (OCT).

(A) Stent edge dissection is defined as disruption of the vessel luminal surface with a visible flap (arrow) at the stent edge.

(B) Incomplete stent apposition is defined as separation of the inner surface of a stent strut from the inner vessel wall (broken circle) by a distance greater than or equal to the axial resolution of OCT plus the width of the stent strut.

(C) Tissue protrusion. In this case, irregular protrusion is identified by the presence of protrusion of material with an irregular surface into the lumen between the stent struts. 


\section{Limitations and Future Directions of OCT}

To date, OCT-guided PCI has not been shown to be superior to IVUS-guided or angiography-guided PCI regarding long-term outcomes. The planned ILUMIEN IV study will be expected to evaluate long-term outcomes in patients randomized to OCTguided PCI versus angiography-guided PCI. Advance in technology is remarkable in this field. Micro-OCT is capable of visualizing cellular and subcellular features such as macrophages and endothelial cells with $1-\mu \mathrm{m}$ resolution, which may enable more accurate diagnosis of plaque erosion. ${ }^{88)}$ Catheter-based micro-OCT imaging is on the horizon. ${ }^{89)}$ Hybrid intravascular imaging modalities are being developed. Combined OCT-IVUS enables more accurate assessment of plaque composition and structure. ${ }^{90)}$ OCT-near infrared fluorescence imaging can image and quantify plaque inflammation. ${ }^{91)}$ OCT-near infrared autofluorescence imaging ${ }^{92)}$ and OCT-near infrared spectroscopy imaging ${ }^{93)}$ provide high-risk plaque composition such as necrotic core lipid. However, whether these new systems have clinical value needs to be tested.

\section{Conclusions}

OCT has been used as a great research tool for a better understanding of in vivo pathobiology of coronary atherosclerosis. In clinical settings, OCT guidance is useful for daily practices to evaluate plaque characteristics of culprit and non-culprit lesions, optimize PCI procedures, and predict future events. OCT may also contribute to the selection of tailored management and treatment strategy depending on the etiology of ACS, especially plaque erosion. It is expected that the clinical value of OCT will be established when upcoming clinical trials demonstrate the superiority of OCT-guided PCI over angiography-guided PCI.

\section{Acknowledgments}

The authors thank all the contributors and all the institutions of the MGH OCT Registry. Dr. Jang's research is supported by Mr. and Mrs. Michael and Kathryn Park, and by Mrs. and Mr. Gill and Allan Gray.

\section{Disclosure Statement}

Dr. Sugiyama is supported in part by the grant from Strategic International Research Collaboration Program with Harvard Medical School to Cultivate Professionals with Knowledge and Humanity from Japan Society for the Promotion of Science, and the subvention from Sumitomo Life Welfare and Culture Foundation. Dr. Jang has received educational grants and consulting fees from Abbott Vascular and financial support from Medicure Inc.

\section{References}

1) Gruentzig A: Results from coronary angioplasty and implications for the future. Am Heart J 1982; 103: 779-783

2) Sigwart U, Puel J, Mirkovitch V, et al: Intravascular stents to prevent occlusion and restenosis after transluminal angioplasty. N Engl J Med 1987; 316: 701-706

3) Sousa JE, Costa MA, Abizaid A, et al: Lack of neointimal proliferation after implantation of sirolimus-coated stents in human coronary arteries: a quantitative coronary angiography and three-dimensional intravascular ultrasound study. Circulation 2001; 103: 192-195

4) Ormiston JA, Serruys PW, Regar E, et al: A bioabsorbable everolimus-eluting coronary stent system for patients with single de-novo coronary artery lesions (ABSORB): a prospective open-label trial. Lancet 2008; 371: 899-907

5) Yock PG, Linker DT, White NW, et al: Clinical applications of intravascular ultrasound imaging in atherectomy. Int J Cardiovasc Imaging 1989; 4: 117-125.

6) Potkin BN, Bartorelli AL, Gessert JM, et al: Coronary artery imaging with intravascular high-frequency ultrasound. Circulation 1990; 81: 1575-1585

7) Tobis JM, Mallery J, Mahon D, et al: Intravascular ultrasound imaging of human coronary arteries in vivo. Analysis of tissue characterizations with comparison to in vitro histological specimens. Circulation 1991; 83: 913-926

8) Yock PG, Fitzgerald PJ, Linker DT, et al: Intravascular ultrasound guidance for catheter-based coronary interventions. J Am Coll Cardiol 1991; 17: 39B-45B

9) Spears JR, Marais HJ, Serur J, et al: In vivo coronary angioscopy. J Am Coll Cardiol 1983; 1: 1311-1314

10) Spears JR, Spokojny AM, Marais HJ: Coronary angioscopy during cardiac catheterization. J Am Coll Cardiol 1985; 6: 93-97

11) Ramee SR, White CJ, Collins TJ, et al: Percutaneous angioscopy during coronary angioplasty using a steerable microangioscope. J Am Coll Cardiol 1991; 17: 100-105

12) Huang D, Swanson EA, Lin CP, et al: Optical coherence tomography. Science 1991; 254: 1178-1181

13) Brezinski ME, Tearney GJ, Bouma BE, et al: Optical coherence tomography for optical biopsy. Properties and demonstration of vascular pathology. Circulation 1996; 93: 1206-1213

14) Tearney GJ, Brezinski ME, Boppart SA, et al: Images in cardiovascular medicine. Catheter-based optical imaging of a human coronary artery. Circulation 1996; 94: 3013

15) Yabushita H, Bouma BE, Houser SL, et al: Characterization of human atherosclerosis by optical coherence tomography. Circulation 2002; 106: 1640-1645

16) Jang IK, Bouma BE, Kang DH, et al: Visualization of coronary atherosclerotic plaques in patients using optical coherence tomography: comparison with intravascular ultrasound. J Am Coll Cardiol 2002; 39: 604-609

17) Fujimoto JG, Boppart SA, Tearney GJ, et al: High resolution in vivo intra-arterial imaging with optical coherence tomography. Heart 1999; 82: 128-133

18) Kume T, Akasaka T, Kawamoto $T$, et al: Measurement of the 
thickness of the fibrous cap by optical coherence tomography. Am Heart J 2006; 152: 755.e1-755.e4.

19) Tearney GJ, Regar E, Akasaka T, et al: Consensus standards for acquisition, measurement, and reporting of intravascular optical coherence tomography studies: a report from the International Working Group for Intravascular Optical Coherence Tomography Standardization and Validation. J Am Coll Cardiol 2012; 59: 1058-1072

20) Virmani R, Kolodgie FD, Burke AP, et al: Lessons from sudden coronary death: a comprehensive morphological classification scheme for atherosclerotic lesions. Arterioscler Thromb Vasc Biol 2000; 20: 1262-1275

21) Takano M, Jang IK, Inami S, et al: In vivo comparison of optical coherence tomography and angioscopy for the evaluation of coronary plaque characteristics. Am J Cardiol 2008; 101: 471476

22) Thieme T, Wernecke KD, Meyer R, et al: Angioscopic evaluation of atherosclerotic plaques: validation by histomorphologic analysis and association with stable and unstable coronary syndromes. J Am Coll Cardiol 1996; 28: 1-6

23) Tearney GJ, Yabushita H, Houser SL, et al: Quantification of macrophage content in atherosclerotic plaques by optical coherence tomography. Circulation 2003; 107: 113-119

24) Tian J, Hou J, Xing L, et al: Significance of intraplaque neovascularisation for vulnerability: optical coherence tomography study. Heart 2012; 98: 1504-1509

25) Prabhudesai V, Phelan C, Yang Y, et al: The potential role of optical coherence tomography in the evaluation of vulnerable carotid atheromatous plaques: a pilot study. Cardiovasc Intervent Radiol 2006; 29: 1039-1045

26) Jang IK, Tearney GJ, MacNeill B, et al: In vivo characterization of coronary atherosclerotic plaque by use of optical coherence tomography. Circulation 2005; 111: 1551-1555

27) Kume $T$, Akasaka $T$, Kawamoto $T$, et al: Assessment of coronary arterial thrombus by optical coherence tomography. Am J Cardiol 2006; 97: 1713-1717

28) Virmani R, Burke AP, Farb A, et al: Pathology of the vulnerable plaque. J Am Coll Cardiol 2006; 47: C13-18

29) Kubo T, Imanishi T, Takarada S, et al: Assessment of culprit lesion morphology in acute myocardial infarction: ability of optical coherence tomography compared with intravascular ultrasound and coronary angioscopy. J Am Coll Cardiol 2007; 50: 933-939

30) Tian J, Ren X, Vergallo R, et al: Distinct morphological features of ruptured culprit plaque for acute coronary events compared to those with silent rupture and thin-cap fibroatheroma: a combined optical coherence tomography and intravascular ultrasound study. J Am Coll Cardiol 2014; 63: 2209-2216

31) Ino Y, Kubo T, Tanaka A, et al: Difference of culprit lesion morphologies between ST-segment elevation myocardial infarction and non-ST-segment elevation acute coronary syndrome: an optical coherence tomography study. JACC Cardiovasc Interv 2011; 4: 76-82.

32) Vergallo R, Ren $X$, Yonetsu T, et al: Pancoronary plaque vulnerability in patients with acute coronary syndrome and rup- tured culprit plaque: a 3-vessel optical coherence tomography study. Am Heart J 2014; 167: 59-67

33) Niccoli G, Montone RA, Cataneo L, et al: Morphological-biohumoral correlations in acute coronary syndromes: pathogenetic implications. Int J Cardiol 2014; 171: 463-466

34) Jia H, Abtahian F, Aguirre AD, et al: In vivo diagnosis of plaque erosion and calcified nodule in patients with acute coronary syndrome by intravascular optical coherence tomography. J Am Coll Cardiol 2013; 62: 1748-1758

35) Otsuka F, Joner M, Prati F, et al: Clinical classification of plaque morphology in coronary disease. Nat Rev Cardiol 2014; 11: 379-389

36) Yahagi K, Kolodgie FD, Otsuka F, et al: Pathophysiology of native coronary, vein graft, and in-stent atherosclerosis. Nat Rev Cardiol 2016; 13: 79-98

37) Alfonso F, Paulo M, Gonzalo N, et al: Diagnosis of spontaneous coronary artery dissection by optical coherence tomography. J Am Coll Cardiol 2012; 59: 1073-1079

38) Alfonso F, Bastante T, García-Guimaraes M, et al: Spontaneous coronary artery dissection: new insights into diagnosis and treatment. Coron Artery Dis 2016; 27: 696-706

39) Park HC, Choi SI, Lee JU, et al: Morphological findings in typical variant angina presenting as acute coronary syndrome using optical coherence tomography. J Interv Cardiol 2013; 26: 491-500

40) Shin ES, Ann SH, Singh GB, et al: OCT-defined morphological characteristics of coronary artery spasm sites in vasospastic angina. JACC Cardiovasc Imaging 2015; 8: 1059-1067.

41) Gonzalo N, Serruys PW, Okamura T, et al: Relation between plaque type and dissections at the edges after stent implantation: an optical coherence tomography study. Int J Cardiol 2011; 150: 151-155

42) Zeglin-Sawczuk M, Jang IK, Kato K, et al: Lipid rich plaque, female gender and proximal coronary stent edge dissections. J Thromb Thrombolysis 2013; 36: 507-513

43) Imola F, Occhipinti M, Biondi-Zoccai G, et al: Association between proximal stent edge positioning on atherosclerotic plaques containing lipid pools and postprocedural myocardial infarction (from the CLI-POOL Study). Am J Cardiol 2013; 111: 526-531

44) Ino Y, Kubo T, Matsuo Y, et al: Optical coherence tomography predictors for edge restenosis after everolimus-eluting stent implantation. Circ Cardiovasc Interv 2016; 9: e004231

45) Gogas BD, Garcia-Garcia HM, Onuma Y, et al: Edge vascular response after percutaneous coronary intervention: an intracoronary ultrasound and optical coherence tomography appraisal: from radioactive platforms to first- and second-generation drug-eluting stents and bioresorbable scaffolds. JACC Cardiovasc Interv 2013; 6: 211-221.

46) Tanaka A, Imanishi $T$, Kitabata $H$, et al: Lipid-rich plaque and myocardial perfusion after successful stenting in patients with non-ST-segment elevation acute coronary syndrome: an optical coherence tomography study. Eur Heart J 2009; 30: 13481355

47) Lee $T$, Yonetsu $T$, Koura K, et al: Impact of coronary plaque 
morphology assessed by optical coherence tomography on cardiac troponin elevation in patients with elective stent implantation. Circ Cardiovasc Interv 2011; 4: 378-386

48) Kimura S, Sugiyama T, Hishikari K, et al: Association of intravascular ultrasound- and optical coherence tomography assessed coronary plaque morphology with periprocedural myocardial injury in patients with stable angina pectoris. Circ J 2015; 79: 1944-1953

49) Kini AS, Motoyama S, Vengrenyuk Y, et al: Multimodality intravascular imaging to predict periprocedural myocardial infarction during percutaneous coronary intervention. JACC Cardiovasc Interv 2015; 8: 937-945.

50) Ozaki Y, Tanaka A, Tanimoto T, et al: Thin-cap fibroatheroma as high-risk plaque for microvascular obstruction in patients with acute coronary syndrome. Circ Cardiovasc Imaging 2011; 4: $620-627$

51) Higuma $T$, Soeda $T$, Yamada M, et al: Does residual thrombus after aspiration thrombectomy affect the outcome of primary PCI in patients with ST-segment elevation myocardial infarction?: an optical coherence tomography study. JACC Cardiovasc Interv 2016; 9: 2002-2011.

52) Prati F, Di Vito L, Biondi-Zoccai G, et al: Angiography alone versus angiography plus optical coherence tomography to guide decision-making during percutaneous coronary intervention: the Centro per la Lotta contro l'Infarto-Optimisation of Percutaneous Coronary Intervention (CLI-OPCI) study. EuroIntervention 2012; 8: 823-829

53) Wijns W, Shite J, Jones MR, et al: Optical coherence tomography imaging during percutaneous coronary intervention impacts physician decision-making: ILUMIEN I study. Eur Heart J 2015; 36: 3346-3355

54) Maehara A, Ben-Yehuda O, Ali Z, et al: Comparison of stent expansion guided by optical coherence tomography versus intravascular ultrasound: the ILUMIEN II study (observational study of optical coherence tomography [OCT] in patients undergoing fractional flow reserve [FFR] and percutaneous coronary intervention). JACC Cardiovasc Interv 2015; 8: 1704 1714.

55) Meneveau N, Souteyrand G, Motreff P, et al: Optical coherence tomography to optimize results of percutaneous coronary intervention in patients with non-st-elevation acute coronary syndrome: results of the multicenter, randomized doctors study (does optical coherence tomography optimize results of stenting). Circulation 2016; 134: 906-917

56) Kubo T, Shinke T, Okamura T, et al: Optical frequency domain imaging vs. intravascular ultrasound in percutaneous coronary intervention (OPINION trial): one-year angiographic and clinical results. Eur Heart J 2017; 38: 3139-3147

57) Otake H, Kubo T, Takahashi H, et al: Optical frequency domain imaging versus intravascular ultrasound in percutaneous coronary intervention (OPINION Trial): Results from the OPINION Imaging Study. JACC Cardiovasc Imaging. 2017. Sep 9. doi: 10.1016/j.jcmg.2017.06.021. [Epub ahead of print]

58) Ali ZA, Maehara A, Généreux P, et al: Optical coherence tomography compared with intravascular ultrasound and with angiography to guide coronary stent implantation (ILUMIEN III: OPTIMIZE PCI): a randomised controlled trial. Lancet 2016; 388: 2618-2628

59) Kato K, Yonetsu T, Kim SJ, et al: Nonculprit plaques in patients with acute coronary syndromes have more vulnerable features compared with those with non-acute coronary syndromes: a 3-vessel optical coherence tomography study. Circ Cardiovasc Imaging 2012; 5: 433-440

60) Kato K, Yonetsu T, Kim SJ, et al: Comparison of nonculprit coronary plaque characteristics between patients with and without diabetes: a 3-vessel optical coherence tomography study. JACC Cardiovasc Interv 2012; 5: 1150-1158.

61) Yonetsu T, Kato K, Uemura S, et al: Features of coronary plaque in patients with metabolic syndrome and diabetes mellitus assessed by 3 -vessel optical coherence tomography. Circ Cardiovasc Imaging 2013; 6: 665-673

62) Kato K, Yonetsu T, Jia H, et al: Nonculprit coronary plaque characteristics of chronic kidney disease. Circ Cardiovasc Imaging 2013; 6: 448-456

63) Xing L, Higuma $T$, Wang $Z$, et al: Clinical significance of lipid-rich plaque detected by optical coherence tomography: a 4-year follow-up study. J Am Coll Cardiol 2017; 69: 2502 2513

64) Naghavi M, Libby P, Falk E, et al: From vulnerable plaque to vulnerable patient: a call for new definitions and risk assessment strategies: Part I. Circulation 2003; 108: 1664-1672

65) Komukai K, Kubo T, Kitabata H, et al: Effect of atorvastatin therapy on fibrous cap thickness in coronary atherosclerotic plaque as assessed by optical coherence tomography: the EASY-FIT study. J Am Coll Cardiol 2014; 64: 2207-2217

66) Hou J, Xing L, Jia H, et al: Comparison of intensive versus moderate lipid-lowering therapy on fibrous cap and atheroma volume of coronary lipid-rich plaque using serial optical coherence tomography and intravascular ultrasound imaging. Am J Cardiol 2016; 117: 800-806

67) Minami Y, Hou J, Xing L, et al: Serial optical coherence tomography and intravascular ultrasound analysis of gender difference in changes of plaque phenotype in response to lipid-lowering therapy. Am J Cardiol 2016; 117: 1890-1895

68) Hong SJ, Kim BK, Shin DH, et al: Effect of intravascular ultrasound-guided vs angiography-guided everolimus-eluting stent implantation: the ivus-xpl randomized clinical trial. JAMA 2015; 314: 2155-2163

69) Prati F, Romagnoli E, Burzotta F, et al: Clinical impact of OCT findings during PCI: The CLI-OPCI II Study. JACC Cardiovasc Imaging 2015; 8: 1297-1305.

70) Gonzalo N, Serruys PW, Okamura T, et al: Optical coherence tomography assessment of the acute effects of stent implantation on the vessel wall: a systematic quantitative approach. Heart 2009; 95: 1913-1919

71) Prati F, Guagliumi G, Mintz GS, et al: Expert review document part 2: methodology, terminology and clinical applications of optical coherence tomography for the assessment of interventional procedures. Eur Heart J 2012; 33: 2513-2520

72) Bouma BE, Tearney GJ, Yabushita H, et al: Evaluation of intra- 
coronary stenting by intravascular optical coherence tomography. Heart 2003; 89: 317-320

73) Kubo T, Imanishi $\mathrm{T}$, Kitabata $\mathrm{H}$, et al: Comparison of vascular response after sirolimus-eluting stent implantation between patients with unstable and stable angina pectoris: a serial optical coherence tomography study. JACC Cardiovasc Imaging 2008; 1: 475-484.

74) Kume T, Okura H, Miyamoto $Y$, et al: Natural history of stent edge dissection, tissue protrusion and incomplete stent apposition detectable only on optical coherence tomography after stent implantation - preliminary observation - . Circ J 2012; 76: 698-703

75) Kawamori H, Shite J, Shinke T, et al: Natural consequence of post-intervention stent malapposition, thrombus, tissue prolapse, and dissection assessed by optical coherence tomography at mid-term follow-up. Eur Heart J Cardiovasc Imaging 2013; 14: 865-875

76) Soeda T, Uemura S, Park SJ, et al: Incidence and clinical significance of poststent optical coherence tomography findings: one-year follow-up study from a multicenter registry. Circulation 2015; 132: 1020-1029

77) Radu MD, Räber L, Heo J, et al: Natural history of optical coherence tomography-detected non-flow-limiting edge dissections following drug-eluting stent implantation. EuroIntervention 2014; 9: 1085-1094

78) Gutiérrez-Chico JL, Wykrzykowska J, Nüesch E, et al: Vascular tissue reaction to acute malapposition in human coronary arteries: sequential assessment with optical coherence tomography. Circ Cardiovasc Interv 2012; 5: 20-29

79) Im E, Kim BK, Ko YG, et al: Incidences, predictors, and clinical outcomes of acute and late stent malapposition detected by optical coherence tomography after drug-eluting stent implantation. Circ Cardiovasc Interv 2014; 7: 88-96

80) Sugiyama T, Kimura S, Ohtani H, et al: Relationship between quantities of tissue prolapse after percutaneous coronary intervention and neointimal hyperplasia at follow-up on serial optical coherence tomography examination. Int J Cardiol 2017; 241: 470-477

81) Sohn J, Hur SH, Kim IC, et al: A comparison of tissue prolapse with optical coherence tomography and intravascular ultrasound after drug-eluting stent implantation. Int J Cardiovasc Imaging 2015; 31: 21-29

82) Sugiyama T, Kimura S, Akiyama D, et al: Quantitative assessment of tissue prolapse on optical coherence tomography and its relation to underlying plaque morphologies and clinical outcome in patients with elective stent implantation. Int J Cardiol 2014; 176: 182-190

83) Bryniarski KL, Tahk SJ, Choi SY, et al: Clinical, angiographic, IVUS, and OCT predictors for irregular protrusion after coronary stenting. EuroIntervention 2017; 12: e2204-e2211

84) O’ Gara PT, Kushner FG, Ascheim DD, et al: 2013 ACCF/AHA guideline for the management of ST-elevation myocardial infarction. Circulation 2013; 127: e362-e425.

85) Amsterdam EA, Wenger NK, Brindis RG, et al: 2014 AHA/ ACC guideline for the management of patients with non-ST-elevation acute coronary syndromes: a report of the American College of Cardiology/American Heart Association Task Force on Practice Guidelines. Circulation 2014; 130: e344-e426.

86) Jia H, Dai J, Hou J, et al: Effective anti-thrombotic therapy without stenting: intravascular optical coherence tomography-based management in plaque erosion (the EROSION study). Eur Heart J 2017; 38: 792-800

87) Prati F, Uemura S, Souteyrand G, et al: OCT-based diagnosis and management of STEMI associated with intact fibrous cap. JACC Cardiovasc Imaging 2013; 6: 283-287.

88) Liu L, Gardecki JA, Nadkarni SK, et al: Imaging the subcellular structure of human coronary atherosclerosis using micro-optical coherence tomography. Nat Med 2011; 17: 1010-1014

89) Yin B, Chu KK, Liang CP, et al: $\mu \mathrm{OCT}$ imaging using depth of focus extension by self-imaging wavefront division in a common-path fiber optic probe. Opt Express 2016; 24: 5555-5564

90) Li J, Ma T, Jing J, et al: Miniature optical coherence tomography-ultrasound probe for automatically coregistered three-dimensional intracoronary imaging with real-time display. J Biomed Opt 2013; 18: 100502

91) Verjans JW, Osborn EA, Ughi GJ, et al: Targeted near-infrared fluorescence imaging of atherosclerosis: clinical and intracoronary evaluation of indocyanine green. JACC Cardiovasc Imaging 2016; 9: 1087-1095.

92) Ughi GJ, Wang H, Gerbaud E, et al: Clinical characterization of coronary atherosclerosis with dual-modality OCT and near-infrared autofluorescence imaging. JACC Cardiovasc Imaging 2016; 9: 1304-1314.

93) Fard AM, Vacas-Jacques P, Hamidi E, et al: Optical coherence tomography--near infrared spectroscopy system and catheter for intravascular imaging. Opt Express 2013; 21: 3084930858 